\title{
"Side effects affected my daily activities a lot": a qualitative exploration of the impact of contraceptive side effects in Bangladesh
}

This article was published in the following Dove Press journal:

Open Access Journal of Contraception

10 July 2017

Number of times this article has been viewed

\author{
Aparna Jain' \\ Laura Reichenbach' \\ Iqbal Ehsan ${ }^{2}$ \\ Ubaidur Rob ${ }^{2}$
}

'Evidence Project, Population Council, Washington, DC, USA; ${ }^{2}$ Evidence Project, Population Council, Dhaka, Bangladesh
Correspondence: Aparna Jain Population Council, 430I Connecticut Ave, NW \#208, Washington, DC 20008, USA

Tel + I 202237943 I

Email apjain@popcouncil.org
Purpose: In a country like Bangladesh that has made great progress in contraceptive use with one of the lowest levels of fertility and highest levels of contraceptive use, understanding what factors influence women's decisions to discontinue a contraceptive method and not switch to a new method is critical in designing interventions and programs that will help enable Bangladesh to reach its FP2020 goals. Research on side effects has focused on physical manifestations like headaches, moodiness, abdominal pain, and menstrual irregularities. While physical effects alone may stop women from continuing a contraceptive method, less is known about how side effects influence women's daily activities and lives. The purpose of this study is to understand the ways that side effects affect Bangladeshi women's participation in different social settings. Methods: Thirty-five in-depth interviews with married women who recently discontinued or switched to a different contraceptive method were conducted in Sylhet and Khulna Divisions. Interviews explored reasons for discontinuation including experience of side effects and impact of side effects on women's lives.

Results: Key themes emerged including that side effects are not only experienced physically but are barriers to women's participation in many aspects of their lives. The spheres of life that most commonly appeared to be influenced by side effects include religion, household, and sexual intimacy irrespective of method used or residence.

Conclusion: Family planning providers need to be aware of these additional consequences associated with contraceptive side effects to provide tailored counseling that recognizes these issues and helps women to mitigate them. For Bangladesh to achieve its FP2020 goals, understanding the broader context in which family planning decisions are made vis-à-vis side effects is critical to design programs and interventions that meet all the needs of women beyond just their fertility intentions. Keywords: family planning discontinuation and switching, qualitative research, experience of side effects

\section{Introduction}

Unintended pregnancies are a major consequence of contraceptive discontinuation. In 2012 , there were 213 million pregnancies, roughly $40 \%$ (85 million) of which were unintended. ${ }^{1}$ Unintended pregnancies have been linked to many negative health behaviors and outcomes for the mother and child including abortion-related morbidity and mortality, maternal mortality, breastfeeding behaviors, timing of antenatal visits, low birth weight, poor child nutrition and incomplete vaccinations, infant mortality, and depression and anxiety. ${ }^{2,3}$

Recently, it has been shown that across 36 Demographic and Health Survey (DHS) countries, one-third of unintended pregnancies are the result of contraceptive 
discontinuation. ${ }^{4}$ Women discontinue modern contraceptive spacing methods for a variety of reasons including pregnancy desire, need for a more effective method, unintended pregnancy due to failure in use adherence or change in access to services, or opposition from their husband or other family members, among other reasons. While any single factor or a combination of factors can influence a woman's decision making around continued use of a particular contraceptive method, the experience of side effects is one of the leading causes of contraceptive discontinuation worldwide. Approximately one in 10 contraceptive users stops using a method within 12 months of its initiation because of method-related side effects. ${ }^{5}$

Much of the research around side effects to date has focused on the physical manifestations of side effects like headaches, moodiness, abdominal pain, and menstrual irregularities. These physical effects alone may be a major contributing factor in women's decisions to stop using a contraceptive method, but do not provide a complete picture of women's experiences of side effects. Less is known about how side effects influence a woman's daily activities and lives. The purpose of this study is to understand the ways that side effects affect Bangladeshi women's participation in different social settings.

\section{Background}

\section{Why Bangladesh?}

The revised FP2020 goals for Bangladesh are to increase contraceptive prevalence rate to $75 \%$, reduce unmet need to $10 \%$, and reduce contraceptive discontinuation to $20 \%{ }^{6}$ Modern contraceptive use has steadily risen in Bangladesh from $5 \%$ in 1975 to $54 \%$ in 2014 , and the total fertility rate (TFR) is 2.3 births per woman, almost at replacement level. ${ }^{7}$ Contraceptive discontinuation, however, remains at $30 \%$ and unmet need for family planning is $12 \%$. Among injectable, implant, and intrauterine device (IUD) users, the leading cause of contraceptive discontinuation is method-related side effects $(46 \%, 51 \%$, and $47 \%$, respectively), followed by pregnancy desire. In a country like Bangladesh that has made great progress and has some of the lowest levels of fertility and highest levels of contraceptive use, understanding what factors influence women's decision to discontinue a contraceptive method and not switch to a new method is critical to design interventions and programs that will enable Bangladesh to reach its FP2020 goals.

\section{Side effects research}

Previous research on the role of side effects in contraceptive discontinuation has focused primarily on the unwanted physical outcomes of contraceptive method use. Generally, these studies have been quantitative with several qualitative exceptions. To predict contraceptive discontinuation, studies have taken a general approach of asking about all side effects instead of specific types of side effects experienced. ${ }^{8,9}$ A considerable number of studies have used the DHS, which limits its response category to a general term: side effects. ${ }^{5,10-12}$

Other research, however, has shown which specific side effects can lead to the discontinuation of contraceptive methods. Researchers have demonstrated that nausea or vomiting, breast tenderness, mood changes, weight gain, dizziness and nausea, and headaches can all lead to the discontinuation of oral contraceptives (OCs). ${ }^{13-16}$ In South Africa, amenorrhea, vaginal wetness/discharge, weight gain, and spotting led to injectable discontinuation while in Honduras women's experiences of weight gain, dizziness, or heavy bleeding were significantly associated with the discontinuation of injectables, OCs, and IUDs. ${ }^{17,18}$

One of the leading causes of hormonal method discontinuation (IUDs, pills, injectables, and implants) is menstrual irregularities, primarily heavy bleeding. ${ }^{8,17,19-22}$ A longitudinal study in Egypt followed hormonal contraceptive users for 18 months to assess patterns and experiences of menstrual bleeding and found that an additional day of menstrual bleeding increased IUD, injectable, or implant discontinuation by $2 \%-4 \%$, depending on the method. ${ }^{23}$ In Bangladesh, women who used the injectable and experienced heavy bleeding or a non-bleeding-related side effect had faster rates of discontinuation compared to those who reported no method related issues. ${ }^{24}$ Moreover, among implant users in a northern district of Bangladesh, researchers found that close to $59 \%$ reported implant removal because of menstrual irregularities. ${ }^{25}$

The role of side effects in altering a woman's life and her normal activities has been explored by several researchers. A panel study in Honduras revealed a significant relationship between reported side effects interfering with daily life and personal relationships and discontinuation of a baseline method (IUD, implant, or injectable). ${ }^{9}$ Because this study was quantitative, it did not offer insights into the areas of daily life that were affected. A few qualitative studies have demonstrated that side effects can interfere with religious practice, household chores, and loss of productive work time..$^{21,26}$

While studies have demonstrated the importance of looking at how women's lives are affected by side effects, less information is available on how these side effects impact women's participation in multiple spheres of life including relationships with their families and communities, and intimacy with their husbands. The current research study provides information that fills this gap in the literature. 


\section{Methods \\ Data}

Married women were recruited from two Bangladesh divisions: Khulna, located in the southeast, and Sylhet, located in the northwest. These two divisions were selected based on the 2011 DHS TFR rates, where Sylhet had the highest at 3.1 births per woman and Khulna the lowest, at 1.9 births. The contraceptive prevalence rate was $67 \%$ in Khulna compared to $45 \%$ in Sylhet. In both divisions, the modern method mix favored the pill (52\% in Khulna and 54\% in Sylhet) followed by the injectable ( $21 \%$ in Khulna and $14 \%$ in Sylhet).

Two unions (the smallest administrative unit of the country) were selected per division. These unions were located in rural settings. Each union has one Union Health and Family Welfare Centre (UHFWC), and the family welfare assistants (FWAs) of the UHFWC maintain a registry of demographic information and contraception use by couples in their catchment area. Working with the FWAs, the research team used registries to identify eligible women. Inclusion criteria for the study included currently married, between the ages of 15-39 years, and engaged in specific contraceptive use behaviors. The later criterion (also presented in Table 1) required a purposive sampling strategy to target recent contraceptive discontinuers and recent method switchers (of all types of methods) to ensure a broad range of method use was represented. The study results reported here are based on 35 in-depth interviews.

Interview guides asked married women about their stories and specific experiences with using contraception. Topics explored included community perceptions of contraceptives

Table I Interviewed respondents

\begin{tabular}{|c|c|c|c|c|}
\hline \multirow[t]{2}{*}{ User type } & \multirow[t]{2}{*}{$\begin{array}{l}\text { Method } \\
\text { discontinued }\end{array}$} & \multirow[t]{2}{*}{$\begin{array}{l}\text { Method } \\
\text { switched }\end{array}$} & \multicolumn{2}{|c|}{$\begin{array}{l}\text { \# of interviews } \\
\text { completed }\end{array}$} \\
\hline & & & Khulna & Sylhet \\
\hline \multirow[t]{4}{*}{ Discontinuers } & Pill & - & 3 & 2 \\
\hline & Injectable & - & 2 & 2 \\
\hline & Implant & - & 2 & 2 \\
\hline & IUD & - & 0 & 2 \\
\hline \multirow[t]{11}{*}{ Switchers } & Pill & Pill & 2 & 0 \\
\hline & Pill & Injectable & I & 2 \\
\hline & Pill & Implant & I & I \\
\hline & Pill & Vasectomy & 0 & I \\
\hline & Pill & Tubal ligation & 0 & 2 \\
\hline & Injectable & Pill & 1 & 2 \\
\hline & Injectable & Implant & 1 & 0 \\
\hline & Injectable & IUD & I & 1 \\
\hline & Implant & Pill & I & I \\
\hline & IUD & Injectable & I & 0 \\
\hline & IUD & Implant & 1 & 0 \\
\hline Total & & & 17 & 18 \\
\hline
\end{tabular}

Abbreviation: IUD, intrauterine device. overall and of specific methods; personal fertility intentions, factors and people who influenced their decision to use contraception and the method they selected; challenges faced when using a method; and episodes of discontinuation and method switching.

Female interviewers were trained in the study objectives and semi-structured interview guides over a 1-week period. Female interviewers were native Bangla speakers and conducted in-depth interviews in private, confidential locations after obtaining written consent from all respondents. All respondents agreed to participate in the interview. Respondents received airtime credit for their phones in the amount of 150 Bangladeshi Taka. Fieldwork took place from May to June 2015 in Khulna and July to August 2015 in Sylhet. Institutional review board (IRB) approval was obtained from the Population Council/USA IRB.

\section{Analysis}

In-depth interviews were tape recorded, transcribed in Bangla verbatim, and translated into English. Interviewers transcribed their own interviews, which were then reviewed by the research team to assess completeness, provide guidance and suggestions for future interviews, add additional questions, and assess saturation.

All transcripts were reviewed against the tape-recorded interviews for accuracy. A codebook was developed by two researchers using an iterative process where after reviewing the same five discontinuer transcripts and five switcher transcripts in English, each researcher developed an initial codebook, codes were compared against each other, and then one codebook was agreed on. The researchers revisited and revised the codebook after reviewing the next set of transcripts and followed this process until all transcripts were reviewed and a codebook was finalized. High levels of researcher agreement were observed in the codebook development and coding processes. This codebook was then used to code the Bangla transcripts. An inductive process was used to identify categories and themes that emerged from the data. ${ }^{27}$ The coding was conducted in Atlas.ti, version 7.5.15.

\section{Results}

\section{Participant demographics}

Table 2 presents demographic information of method switchers and discontinuers interviewed in this study. Respondents were between the ages of 20 and 39, with a range of 1-4 or more living children. The majority of respondents were married for 10-19 years (47.0\%) and had less than primary 
Table 2 Background demographics of interviewed respondents

\begin{tabular}{ll}
\hline Characteristics & Percent $(\mathbf{n}=\mathbf{3 5})$ \\
\hline Age (years) & 22.9 \\
$20-24$ & 25.7 \\
$25-29$ & 25.7 \\
$30-34$ & 25.7 \\
$35-39$ & \\
Parity & 25.7 \\
I & 25.7 \\
2 & 22.9 \\
3 & 25.7 \\
$4+$ & \\
Marital years & 32.4 \\
$<10$ years & 47.0 \\
I0-19 years & 20.6 \\
20+ years & \\
Education & 25.7 \\
None & 65.7 \\
Primary or less & 8.6 \\
Secondary or more & 17.1 \\
Used menstrual regulation & 17.1 \\
Child death (excludes miscarriage) & \\
Residence & 48.6 \\
Khulna & 51.4 \\
Sylhet &
\end{tabular}

education $(65.7 \%)$. Few respondents had used menstrual regulation or had experienced the death of a child.

\section{Experience of side effects}

The majority of both method discontinuers and method switchers experienced some form of physical side effect related to contraceptive use. Side effects ranged from pain and discomfort like dizziness, headaches, nausea/vomiting, discharge/itchiness, abdominal or hand pain to irregular bleeding (both prolonged and absent). When a woman reported the experience of a side effect, the interviewer then probed by asking if and how the side effect interfered in her life. The following transcript highlights the importance of qualitative interviews to obtain this information:

Interviewer: Why did you stop using this method?

Respondent: I took the implant off because it did not suit me. I was facing some problem.

Interviewer: What problems did you face when you used the implants?

Respondent: I had severe body ache and headache. I also experienced irregular menstruation when I use the implants.

I had my periods after $5 / 6$ months which was unusual!

Interviewer: How did the problem/side effect affect your daily activities?

Respondent: My hands used to hurt badly. I felt pain in my arms when I took heavy things. I have to manage all the household work. So if I feel pain in my hand, I cannot do my regular work like cleaning, cooking, or even couldn't carry my baby. Besides, I didn't have my menstruation, it made me so weak! All my polluted bloods were jammed into my body. Sometime, I feel dizziness after having sex with my husband due to weakness. Before taking implant, I was not as weak! After wearing implant gradually I became weak.

-21 year old, implant discontinuer, Sylhet

The interviews revealed that common side effects impact women's lives in different ways and prevent them from participating in spheres of their life, which factor into their decision making around contraceptive continuation or discontinuation. The following section presents results on the impact of side effect across three main aspects of women's lives: religious life, daily life and family support, and sexual life. These three aspects arose from the interviews and were the most salient themes that emerged.

\section{Religious life}

Many women reported that their experience of side effects influenced their ability to participate in religious activities. Side effects that limited religious participation consisted primarily of vaginal discharge and menstrual bleeding, which made women feel unclean or impure. A mother of two reported that the IUD weakened her and made her thinner but it also caused continuous discharge, which impacted her ability to perform her prayers:

Suppose, I had taken a bath. I took bath for being clean and
pure, didn't I? But I saw again discharge after taking bath!
Could I say my prayer in this situation? Could I read the
Quran with this? No, I could not. I could not say my prayer
and read the Quran. To perform my prayer I had to be pure.
-28 year old, IUD discontinuer, Sylhet

Women also reported that prolonged menstrual bleeding that continued beyond the "normal" number of days for a menstrual cycle prevented them from performing their regular prayers because it is prohibited in Islam and Hinduism to do prayers or go to mosque or temple when menstruating. A 30-year-old, switcher (pill to injectable) and mother of four, said the following about her experience of side effects while on the pill:

By taking pills I faced severe headaches. I had menstruation problems too. It didn't stop! Once it started, it continued for two weeks long which disturbed me so much! I was unable to perform my regular prayer!

-30-year-old, switcher (pill to injectable), Sylhet 
Another mother of four described her experience of side effects while taking the injectable. Though she explained that the extended bleeding she experienced subsided after 2 months, it reappeared after a year:

I continued the injectable for two years. In these two years, I faced some physical problems. After my first injection I suffered from heavy bleeding for two months. It was very painful. Then it decreased gradually and got a regular flow. But one year later I faced this problem again and this time it continued for three months. It was very irritating. I couldn't do my prayers five-times per day due to prolonged bleeding.

-29-year-old, switcher (injectable to implant), Khulna

This quote highlights how a side effect can change throughout the course of a contraceptive use episode and may occur at varying levels of intensities, varying combinations, and at various times.

\section{Daily life and family support}

Side effects affected many respondents' abilities to complete household chores or tend to other responsibilities, which was particularly problematic for them. Domestic responsibilities that could not be completed included cooking, cleaning, attending and caring for children, or carrying heavy items.

In several instances, women reported that the impact of side effects was so debilitating, that at times they needed to lie down in their beds, had accidents, or fell down. A mother of one described her problems while using the implant as follows:

I could not do my household work properly. I couldn't bring water from the pond or collect firewood from outside. I also felt pain in my hand when I carried the water bucket. I had passed those three months very badly.

$$
\text { -36-year-old, switcher (implant to pill), Khulna }
$$

Women who described similar situations also reported that these circumstances were too difficult to manage by themselves. When women were unable to accomplish their household responsibilities, some could rely on their daughters and sons, and in some instances mothers and sisters for support. As described by a mother of three:

I was unable to tolerate the headache and dizziness. After taking pill I immediately felt dizzy! Sometimes I couldn't stand on my feet, I had to sit or lay down in bed. It didn't happen every time but when it happened it affected me seriously. I could not wake up from the bed due to dizziness! My daughter and elder son did all household work.

$$
\text { -33-year-old, pill discontinuer, Sylhet }
$$

Other women, however, did not have the support of family members because they lived far away from their parents or siblings, their children were too young or too old, worked all day or lived elsewhere, or there was no one available in the household to assist during the day. A mother of two describes the lack of family support in this way:

Side effects affected my daily activities a lot. I have two little children and I alone take care of them. Except me, there is no other woman in my house. Rearing two children and at the same time as managing other household work is very laborious tasks. Because of physical weakness and dizziness, I could not manage all the domestic work properly. I have to manage cooking, cleaning, dishwashing, water collecting from the pond, fuel collecting for cooking alone. My fatherin-law and my husband work in the paddy field every day. -22-year-old, injectable discontinuer, Khulna

This same woman went on to explain the verbal abuse she received from her father-in-law and husband when she failed to complete her domestic responsibilities, which factored into her decision to stop using the injectable:

I have to prepare food for them before they return from the field. Sometimes when I fail to cook food on time then they scolded me for being late!

\section{Sexual life}

About one-third of women reported feelings of pain in the abdomen or vagina during sex that sometimes lasted days, which they attributed to contraceptive use. One respondent described it as "fire" in the vagina. Whether this is an accurate medical assessment or misattribution of an underlying undiagnosed reproductive health condition like vaginal prolapse or sexually transmitted disease, it warrants exploration in future research. The pain ranged in severity for each woman. A mother of one who stopped using the injectable described it this way:

During sex I felt pain in my vagina. The pain was continuing for two to three days after intercourse. It felt like my entire abdomen is coming down through the vagina! I felt heaviness in my body.

$$
\text { -26-year-old, injectable discontinuer, Khulna }
$$

Women also reported a loss of sex drive and an inability to perform sexually for their husbands as described by a mother of three children and current implant user:

I feel weak when I am experiencing prolonged menstruation. It is affecting my sex drive. Because of weakness I cannot perform well in the bed and I know it is frustrating for my husband. -31-year-old, switcher (pill to implant), Sylhet 
Several women reported that they were unable to refuse sex with their husbands when they were experiencing side effects, particularly menstruation. An implant user experienced verbal mistreatment and physical abuse when she refused sex with their husbands and described it as follows:

When I didn't give him space for sex (silence for a moment), sometimes he beat me.

-29-year-old, switcher (injectable to implant), Khulna

The same woman, however, goes on to report that she was compelled to have sex with her husband for self-preservation; she feared her husband would seek sex from other women who may have diseases, which he could contract and pass on to her. She describes this in the following way:

If I don't fulfill his wish of sex, he will go to the outside. Then he will become an addict of bad things. That will be harmful for me. I was afraid if he went to the other women and has any kind of diseases, then that will harm me. That's why I didn't refuse him and gave him what he wanted.

\section{Discussion}

The results from this study show that married women in Bangladesh who discontinued or switched to a new contraceptive method did so primarily for reasons associated with contraceptive side effects. This finding is not new and has been shown extensively in studies from many developing countries. This study does, however, provide context for what side effects mean to women and how they affect their routine activities and their relationships with family members, which in turn contributed to their decision to discontinue or switch to a different contraceptive method.

Women in this study reported that menstrual bleeding prevented them from participating in religious activities. In Bangladesh where $90 \%$ of women interviewed were Muslim, ${ }^{7}$ absence from group prayers because of excessive bleeding can bring unwanted attention that requires a reason or explanation. ${ }^{21}$ Many women in Bangladesh restrict their participation in religious rituals and prayers when they are menstruating, as is the social norm. In a recent survey of adolescent girls on menstruation, $95 \%$ reported that they did not engage in religious prayer while menstruating. ${ }^{28}$ The unpredictability of the timing of bleeding as it relates to contraceptive side effects can heighten the challenges of managing the bleeding, particularly around religious festivals and holidays. Furthermore, menstrual side effects are common among pill, injectable, and IUD users. Comprehensive and complete counseling on the different types of menstrual side effects like prolonged bleeding, spotting, and amenorrhea needs to be regularly included in counseling.

In addition to religious life, women's participation in the household was also affected by the experience of side effects. Many women in Bangladesh are the primary domestic caretakers, including activities like chores within the household, agricultural work, or poultry or cattle rearing. Side effects prevented women from continuing these responsibilities, which was shown in another study to cause feelings of guilt. ${ }^{21}$ When this role could not be fulfilled, many women received assistance from family members but many others were rebuked. If women are not able to participate in these household tasks they are, in effect, not able (or less able) to satisfy social expectations. For women who may want to keep their contraceptive use a secret from others, including possibly their husbands, they may have the added pressure of having to "hide" their side effects from others.

Several women in this study encountered verbal and at times physical abuse from their husbands when they refused sex. Domestic violence has been documented as a major issue in Bangladesh, with a number of studies and surveys in both rural and urban areas showing high numbers of women reporting the experience of physical or sexual violence within marriage. In the population-based 2006 Urban Health Survey, $31 \%$ of currently married women reported experiencing some form of physical violence from their husband in the past year. ${ }^{29}$ Other surveys in rural areas report lifetime experience of domestic violence between $42 \%$ and $67 \%{ }^{30,31}$ Men's self-reports of perpetuating physical and/or sexual violence suggest that $75 \%$ of married women in Bangladesh experience such abuse in their lifetime. ${ }^{32}$ Studies have also shown that women who experience physical abuse are more likely to use contraceptive method. ${ }^{33}$ Using pooled DHS data for several South Asian countries, including Bangladesh, researchers found sexual marital violence more likely to be reported among pill users than nonusers. ${ }^{34} \mathrm{~A}$ limitation of our study is that information on previous experiences of abuse from husbands or other family members was not explored.

Another sphere that women reported being affected by contraceptive side effects was sexual relationships, specifically as a result of decreased sexual pleasure. Several women felt that their desire and ability to have sex diminished because of prolonged bleeding and abdominal pain, which reduced their sex drive as well as strained their relationship with their husband. A loss of sexual pleasure or desire resulting from contraceptive use has been shown in the USA. ${ }^{8,22,35,36}$ but has been lacking in the discourse on contraceptive choice and decision making around method continuation and 
switching for women living in developing countries. There is also a need to understand whether these side effects are medical assessments that are associated with contraceptive use or are related to an underlying symptom of disease or disability (for example an sexually transmitted infection).

Learning about the broader context in which familyplanning decisions are made vis-à-vis side effects is critical to design programs and interventions that meet all the needs of women beyond just their fertility intentions. Providers need to be aware of these additional consequences associated with contraceptive side effects to provide tailored counseling that recognizes these issues and helps women to mitigate them. In addition, as part of counseling, providers could share how side effects may affect women's daily lives, and if it happens and a woman is unable to manage it, encourage her to return to the facility and explore using a different method.

If Bangladesh is to meet its FP2020 goals, results of this study suggest that interventions that promote contraceptive continuation (and not continuation of the same method) should consider the role that these additional unwanted consequences of contraceptive use may have in women's decision making. Research shows that in Bangladesh, $61 \%$ of unintended recent births were to women who used contraception but discontinued prior to pregnancy. ${ }^{4}$ These unintended pregnancies could, therefore, have been prevented if, at the time a woman stopped using a method, she successfully adopted a different method. Furthermore, 74\% of Bangladeshi women with an unmet need were past users suggesting that at some point in their lives, ${ }^{37}$ a large number of women with an unmet need overcame barriers to access services, but at the moment of the survey, were not using family planning even though they wanted to postpone their next pregnancy or stop childbearing altogether. It is important to understand the reasons why past users are unable to resume contraceptive use.

\section{Acknowledgments}

The authors would like to thank the participants of this study who provided their valuable time and shared their stories, and the interviewers for their diligence and hard work. The authors would like to acknowledge the comments and suggestions received from Karen Hardee and Kate Gilles on a previous draft. The Evidence Project is made possible by the generous support of the American people through the United States Agency for International Development (USAID) under the terms of cooperative agreement no. AIDOAA-A-13-00087. The contents of this manuscript are the sole responsibility of the Evidence Project and Population
Council and do not necessarily reflect the views of USAID or the USA Government.

\section{Disclosure}

The authors report no conflicts of interest in this work.

\section{References}

1. Sedgh G, Singh S, Hussain R. Intended and unintended pregnancies worldwide in 2012 and recent trends. Stud Fam Plann. 2014;45(3):301-314.

2. Gipson JD, Koenig MA, Hindin MJ. The effects of unintended pregnancy on infant, child, and parental health: a review of the literature. Stud Fam Plann. 2008;39(1):18-38.

3. Malarcher S, Olson L, Hearst N. Unintended pregnancy and pregnancy outcome: equity and social determinants. Equity, Social Determinants and Public Health Programmes. Geneva, Switzerland: World Health Organisation; 2010:177.

4. Jain AK, Winfrey W. Contribution of contraceptive discontinuation to unintended births in 36 developing countries. Stud Fam Plann. 2017.

5. Ali MM, Cleland JG, Shah IH; World Health Organization. Causes and Consequences of Contraceptive Discontinuation: Evidence from 60 Demographic and Health Surveys. Geneva: World Health Organization; 2012:193.

6. FP2020. Commitments, Bangladesh; 2015. Available from: http://www. familyplanning2020.org/entities/70/commitments. Accessed April 21, 2017.

7. National Institute of Population Research and Training (NIPORT), Mitra and Associates, and ICF International. Bangladesh Demographic and Health Survey 2014. Dhaka, Bangladesh, and Rockville, Maryland, USA: NIPORT, Mitra and Associates, and ICF International; 2016.

8. Moreau C, Cleland K, Trussell J. Contraceptive discontinuation attributed to method dissatisfaction in the United States. Contraception. 2007;76(4):267-272.

9. Barden-O'Fallon J, Speizer I, Rodriguez F, Calix J. Experience with side effects among users of injectables, the IUD, and oral contraceptive pills in four urban areas of Honduras. Health Care Women Int. 2009;30(6):475-483.

10. Blanc AK, Tsui AO, Croft TN, Trevitt JL. Patterns and trends in adolescents' contraceptive use and discontinuation in developing countries and comparisons with adult women. Intl Perspect Sex Reprod Health 2009;35(2):63-71.

11. Curtis S, Evens E, Sambisa W. Contraceptive discontinuation and unintended pregnancy: an imperfect relationship. Int Perspect Sex Reprod Health. 2011;37(2):58-66.

12. Khan MA. Factors associated with oral contraceptive discontinuation in rural Bangladesh. Health Policy Plan. 2003;18(1):101-108.

13. Savabi Esfahany M, Fadaei S, Yousefy A. Use of combined oral contraceptives: retrospective study in Isfahan, Islamic Republic of Iran. East Mediterr Health J. 2006;12(3-4):417-422.

14. Rosenberg MJ, Waugh MS, Meehan TE. Use and misuse of oral contraceptives: risk indicators for poor pill taking and discontinuation. Contraception. 1995;51(5):283-288.

15. Zafar Ullah AN, Humble ME. Determinants of oral contraceptive pill use and its discontinuation among rural women in Bangladesh. Reprod Med Biol. 2006;5(2):111-121.

16. Westhoff CL, Heartwell S, Edwards S, et al. Oral contraceptive discontinuation: do side effects matter? Am J Obstet Gynecol. 2007;196(4):412. e411-412. e417.

17. Smit J, McFadyen L, Zuma K, Preston-Whyte E. Vaginal wetness: an underestimated problem experienced by progestogen injectable contraceptive users in South Africa. Soc Sci Med. 2002;55(9):1511-1522.

18. Barden-O'Fallon J, Speizer IS, Cálix J, Rodriguez F. Contraceptive discontinuation among Honduran women who use reversible methods. Stud Fam Plann. 2011;42(1):11-20. 
19. Reuter S, Smith A. Implanon ${ }^{\circledR}$ : user views in the first year across three family planning services in the Trent Region, UK. Eur J Contracept Reprod Health Care. 2003;8(1):27-36.

20. Wong RC, Bell RJ, Thunuguntla K, McNamee K, Vollenhoven B. Implanon users are less likely to be satisfied with their contraception after 6 months than IUD users. Contraception. 2009;80(5):452-456.

21. Bradley JE, Alam ME, Shabnam F, Beattie TS. Blood, men and tears: keeping IUDs in place in Bangladesh. Cult Health Sex. 2009;11(5):543-558.

22. Sanders SA, Graham CA, Bass JL, Bancroft J. A prospective study of the effects of oral contraceptives on sexuality and well-being and their relationship to discontinuation. Contraception. 2001;64(1):51-58.

23. Tolley E, Loza S, Kafafi L, Cummings S. The impact of menstrual side effects on contraceptive discontinuation: findings from a Longitudinal Study in Cairo, Egypt. Int Fam Plann Perspect. 2005;31(1):15-23.

24. Riley AP, Stewart MK, Chakraborty J. Program- and method-related determinants of first DMPA use duration in rural Bangladesh. Stud Fam Plann. 1994;25(5):255-267.

25. Huda FA, Chowdhuri S, Rabbi Sirajuddin MF. Importance of appropriate counselling in reducing early discontinuation of norplant in a northern district of Bangladesh. J Health Popul Nutr. 2014;32(1):142-148.

26. Kibira SP, Muhumuza C, Bukenya JN, Atuyambe LM. "I spent a full month bleeding, I thought I was going to die..." A qualitative study of experiences of women using modern contraception in Wakiso district, Uganda. PLoS One. 2015;10(11):e0141998.

27. Glaser BG, Strauss AL. The Discovery of Grounded Theory: Strategies for Qualitative Research. New Brunswich, USA, London, UK: Transaction publishers; 2009.

28. Muhit I, Chowdhury ST. Menstrual hygiene condition of adolescent schoolgirls at Chittagong division in Bangladesh. Int J Sci Technol Res. 2013;2(6):58-62.
29. Sambisa W, Angeles G, Lance PM, Naved RT, Thornton J. Prevalence and correlates of physical spousal violence against women in slum and nonslum areas of urban Bangladesh. $J$ Interpers Violence. 2011;26(13):2592-2618.

30. Garcia-Moreno C, Jansen HA, Ellsberg M, Heise L, Watts CH. Prevalence of intimate partner violence: findings from the WHO multi-country study on women's health and domestic violence. Lancet. 2006;368(9543):1260-1269.

31. Bates LM, Schuler SR, Islam F, Islam MK. Socioeconomic factors and processes associated with domestic violence in rural Bangladesh. Int Fam Plann Perspect. 2004;30(4):190-199.

32. Silverman JG, Gupta J, Decker MR, Kapur N, Raj A. Intimate partner violence and unwanted pregnancy, miscarriage, induced abortion, and stillbirth among a national sample of Bangladeshi women. BJOG. 2007;114(10):1246-1252.

33. Dalal K, Andrews J, Dawad S. Contraception use and associations with intimate partner violence among women in Bangladesh. J Biosoc Sci. 2012;44(1):83-94.

34. Raj A, McDougal L, Reed E, Silverman JG. Associations of marital violence with different forms of contraception: cross-sectional findings from South Asia. Int J Gynecol Obstet. 2015;130:E56-E61.

35. Higgins JA, Hoffman S, Graham CA, Sanders SA. Relationships between condoms, hormonal methods, and sexual pleasure and satisfaction: an exploratory analysis from the Women's Well-Being and Sexuality Study. Sex Health. 2008;5(4):321-330.

36. Higgins JA, Hirsch JS. Pleasure, power, and inequality: incorporating sexuality into research on contraceptive use. Am J Public Health. 2008;98(10):1803-1813.

37. Jain AK, Obare F, RamaRao S, Askew I. Reducing unmet need by supporting women with met need. Int Perspect Sex Reprod health. 2013;39(3):133-141.
Open Access Journal of Contraception

\section{Publish your work in this journal}

Open Access Journal of Contraception is an international, peerreviewed, open access, online journal, publishing original research, reports, reviews and commentaries on all areas of contraception. In addition to clinical research, demographics and health-related aspects, the journal welcomes new findings in animal and preclinical studies

\section{Dovepress}

relating to understanding the biological mechanisms and practical development of new contraceptive agents. The manuscript management system is completely online and includes a very quick and fair peer-review system. Visit http://www.dovepress.com/testimonials.php to read real quotes from published authors. 